The Making of the National Health Service.

By John E. Pater. King's Fund Historical Series 1. Pp. xii +210 , illustrated. King Edward's Hospital Fund for London, London, 1981. £10.00.

At a time when the fundamental administrative structure and financing of the National Health Service are under continual critical review, it is valuable to have a factual account of the negotiations which led up to its formation. This volume, written by a former senior civil servant in the Ministry of Health and later DHSS, provides this evidence, on the basis of a carefully researched study of the documents now recently made public and from his own personal experience. It is clear and concise, in so far as it is possible to compress within a small compass the innumerable reports, discussions and negotiations which emanated from all the bodies concerned. It does not, however, make easy reading nor is it a record which can be perused with any sense of pride in our profession or of admiration for the political figures. The author is perhaps too detached an observer and seeks to play down the personalities of the protagonists. To many of us at the time they seemed to be giants, who are not easily reduced to civil service prose. If $\mathrm{Mr}$ Pater admires anyone outside the bureaucracy it is Aneurin Bevan, and he comes through as a welcome new broom with a much more acute sense of political possibilities than any of his ministerial predecessors and certainly more astute than the doctors.

It is sad, looking back on these events, that so much was decided on such a limited platform of information and discussion. Clearly Beveridge had thought through national insurance and produced an attractive and workable scheme. Equally clearly he had not adequately explored the health field and in wartime circumstances all the arguments were confined within the narrow limits of experience with the 'panel' and with the reactions between voluntary and local authority hospitals as modified by the Emergency Medical Service. So great a matter deserved a wider perspective. It now seems extraordinary that the 2 vital points on which the BMA held out to the last concerned the abolition of the sale of practices, for which they were offered handsome compensation, and the basic salary of GPs, which they declared would totally undermine their independence, yet which in the shape of a practice allowance they gladly accepted a few years later.

We can be grateful that the profession held out against a full-time salaried service. We must be a little ashamed that most of us were otherwise so concerned with small issues and in such haste to get on with our jobs that we gave no study in depth to the far-reaching consequences of these momentous decisions.

\section{The MRCGP Study Book}

By T. A. I. Bouchier Hayes, John Fry, Eric Gambrill, Alistair Moulds and K. Young. Pp. 175. Update Publications in association with MTP Press, Lancaster, 1981. $£ 11.50$ (hardback) $£ 9.75$ (paperback).

The membership examination of the Royal College of General Practitioners is based on 5 parts: 3 written and 2 oral. First, there is a paper of the traditional variety with 3 questions which have to be answered in essay formTraditional Essay Question (TEQ). Second, there is a Modified Essay Question (MEQ); a clinical problem is unfolded stage by stage and the candidate is asked, at each stage, to respond to the problem at that stage by writing down what he would do. As so often happens in real life, complications occur-frequently of an unexpected nature (even threats of litigation) to enable the examiners to assess the candidate's knowledge, understanding and approach to all these situations. The third written paper is a series of Multiple Choice Questions (MCQ).
The first oral exam is based on a diary (the 'log diary which each candidate has to submit of his practice profile and a list of 50 patients he has seen (theoretically 50 consecutive patients!). The examiner selects from that list patients discuss. The second oral covers almost any topic in the fieff of primary care.

There are 2 skills essential to the passing of any examina

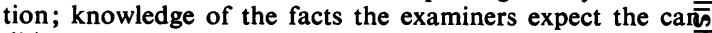
didate to possess and the ability to present the knowledge the candidate does possess in a way that is understandable and acceptable to the examiners.

The authors of this book have had considerable experience in the study and marking of the MRCGP exam. Each time (D paper is explained and sample questions provided, with which the reader (assuming he is a candidate for a futures exam) can test himself. Answers are provided with comment\$ The last 2 chapters explain some of the thought process of the examiners of the oral examinations and offer guidanceg on how to deal with these.

I have no hesitation in strongly recommending this book to anyone contemplating sitting the MRCGP examination- however much he (or she) thinks he knows. No one (to mis knowledge) has ever got $100 \%$ marks! Anyone contemplato ing setting a similar examination elsewhere will also beneff from reading this brief volume. (It took this reviewer less than one evening - though he did not attempt to answer and
of the questions!)

There are points about the book I could criticise, for example the use of unexplained abbreviations. I still do not know what SOA (p. 91) stands for. There is also somethin of a slip-up in the references on pages 161 and 162 to the log diary that follows. The page numbers given in these referencs should refer to the actual page numbers in the book and not as I think they do-refer to the pages in the authors' tred draft.

I am sure there is going to be a second edition. I sugisesh the authors do what the examiners of the RCGP themsers do: offer the book in draft form to a group of experienced examiners for comment on detail.

\section{Occupational Health Practice}

Edited by R. S. F. Schilling. 2nd edn. Pp. xviii $+63 Q_{-}^{2}$ Butterworths, London, 1981. $£ 18.00$.

One of the criticisms in the past in the field of occupational health was the lack of adequate text books on the subject This field of practice is a very wide one making it difficult encompass all the different aspects. The student had to search the specialist journals, read monographs and depend a great deal on word-of-mouth teaching. All this is changing and there are some excellent text books available. This new edition is one such a book.

Professor Schilling has gathered together the contribug tions of many of the staff and visiting lecturers of his formes department at the London School of Hygiene and Tropical Medicine and produced a series of monographs covering nearly every aspect of the subject. Based as it is on the teach ing programme of his Department of Occupational Health it is aimed first and foremost at the postgraduate students. studying for the Diploma of Industrial Medicine, M.Sc. and now the new Faculty of Occupational Medicine examinătions. For them it is essential reading and will fill any gaps in their lectures. It will particularly appeal to students frotof overseas who over the years have filled many places on the courses provided by Schilling and his team and whose countries show an ever expanding interest in this specialite This fact is well recognized in a chapter on the specia problems in the developing countries by Dr El-Batawi frow W.H.O. The needs of the practising Occupational Physician are equally well served. 